\title{
Electrical Resistivity of Vitreous Ternary Lithium-Sodium Silicates
}

\author{
Simon W. Strauss ${ }^{1}$
}

\begin{abstract}
Resistivities of vitreous lithium disilicate, sodium disilicate, and selected ternary lithium-sodium silicates were measured in the range $150^{\circ}$ to $230^{\circ} \mathrm{C}$. The resulting data are given as $\log$ resistivity-composition isotherms. A correlation between heats of activation and composition is also presented. The composition containing approximately equimolar quantities of lithium oxide and sodium oxide showed a maximum value on the resistivitycomposition isotherms as well as on the heat of activation-composition curve. The resistivities of the glasses were interpreted in terms of the structure of glass.
\end{abstract}

\section{Introduction}

Developments in electronic and related fields have emphasized the need for electrical insulating materials that can be used at elevated temperatures. Results of an investigation conducted in this laboratory showed that ceramic coatings merit serious consideration in the field of high-temperature electrical insulation [1]. ${ }^{2}$ From the standpoint of high electrical resistivity, alkali-free ceramic coatings are preferable to those containing alkali ions. In some cases, however, where the fusion point of the frit is high, some alkali ions are added in order to obtain workable coatings. In these instances it would be desirable to add alkali ions in such proportions as to minimize their effect upon resistivity and still yield a workable coating.

Some investigators have conducted studies on the electrical properties of glasses containing two species of alkali ions $[2,3,4,5]$. Their data indicated that when a mixture of two alkali ions was substituted for the same mole percent of either one, values for dielectric constant or loss when plotted against composition showed a minimum on the curve. Electrode potential and resistivity showed a maximum value on a property-composition curve. Dale, Pegg, and Stanworth [2] studied the electrical properties of five compositions in the system $50 \mathrm{SiO}_{2}$ :$18 \mathrm{~B}_{2} \mathrm{O}_{3}: 5 \mathrm{Al}_{2} \mathrm{O}_{3}:(27-x) \mathrm{Li}_{2} \mathrm{O}: x \mathrm{Na}_{2} \mathrm{O}$. Their data on the room-temperature resistivities indicated that the glass that contained equimolar quantities of sodium oxide and lithium oxide showed a maximum value on the resistivity-composition curve. It was considered desirable to study a three-component, lithium-sodium silicate system instead of a fivecomponent system such as the one cited, because any effects produced by the presence of additional oxides would be eliminated. The data obtained on a three-component system should therefore lend themselves more readily to interpretation. The present paper describes results obtained on glasses in the

1 Present address Naval Research Laboratory, Washington, D. C.

${ }^{2}$ Figures in brackets indicate the literature references at the end of this paper. system $x \mathrm{Li}_{2} \mathrm{O}:(1-x) \mathrm{Na}_{2} \mathrm{O}: 2 \mathrm{SiO}_{2}$ whose resistivities were measured in the range $150^{\circ}$ to $230^{\circ} \mathrm{C}$.

\section{Experimental}

The materials used were reagent grade lithium carbonate and sodium carbonate, and quartz crystals [6] pulverized to pass a U. S. Standard No. 40 sieve. The batch compositions of the glasses are given in table 1 . The method of preparing the experi-

TABLE 1. Batch compositions of glasses in the system $x \mathrm{Li}_{2} \mathrm{O}$ : $(1-x) \mathrm{Na}_{2} \mathrm{O}: 2 \mathrm{SiO}_{2}$

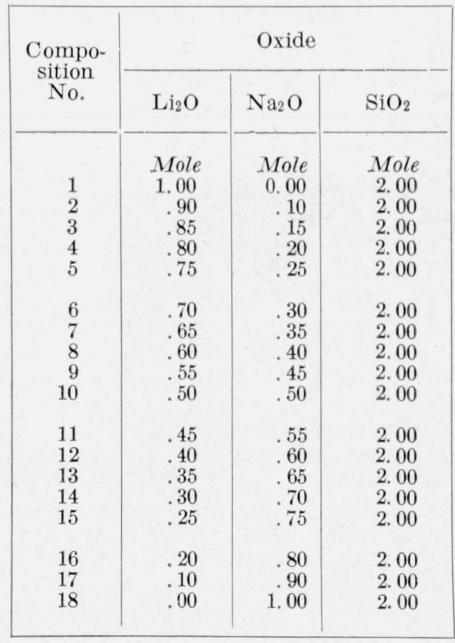

mental batches, the test equipment used to measure the resistivities of the glass specimens, and the method of test have been described in detail elsewhere [6]. Measurements were made at $10 \mathrm{deg}$ $\mathrm{C}$ intervals in the range $150^{\circ}$ to $230^{\circ} \mathrm{C}$. A 200-v battery line was used as the emf source. The resistivity values were calculated from the current, voltage, and dimensions of the specimens. Values for heats of activation, $\Delta H^{*}$, were calculated from the slopes of curves obtained by plotting log resistivity against the reciprocal of the absolute temperature. 


\section{Results and Discussion}

Figure 1 gives resistivity-composition isotherms at 150,200 , and $230^{\circ} \mathrm{C}$ for vitreous lithium disilicate, sodium disilicate, and selected lithium-sodium silicates. A heat-of-activation-composition curve for these glasses is given in figure 2 . These curves show that resistivities and heats of activation of the ternary compositions are higher than those of the binary glasses, the values, in each case, reaching a maximum for a glass containing approximately equimolar quantities of lithium oxide and sodium oxide. The position of the resistivity maximum is close to that reported for the five-component lithium-sodium-aluminum borosilicate [2]. The data show that two compositions, one on each side of the maximum on the curve, can yield glasses having a given resistivity. This observation holds true for compositions whose resistivity values are equal to or greater than that of lithium disilicate.

The fact that the resistivities of the ternary compositions were higher than those of the binary glasses, even though the total number of ions was kept constant for all glasses, suggests that a tightening of the structure probably occurred in the ternary glasses. Smyth [3], in discussing the distribution of size of interstices in glass, states: "Because of the irregularity of the vitreous structure there should be quite a wide spread in size of the interstices." As a first approximation, Smyth assumes a Gaussian distribution. Applying such reasoning to explain why a mixture of two alkali ions in a glass gives much lower dielectric losses than the same concentration of one alkali, he stated: "When a mixture of two ions is substituted for the same mole percent of

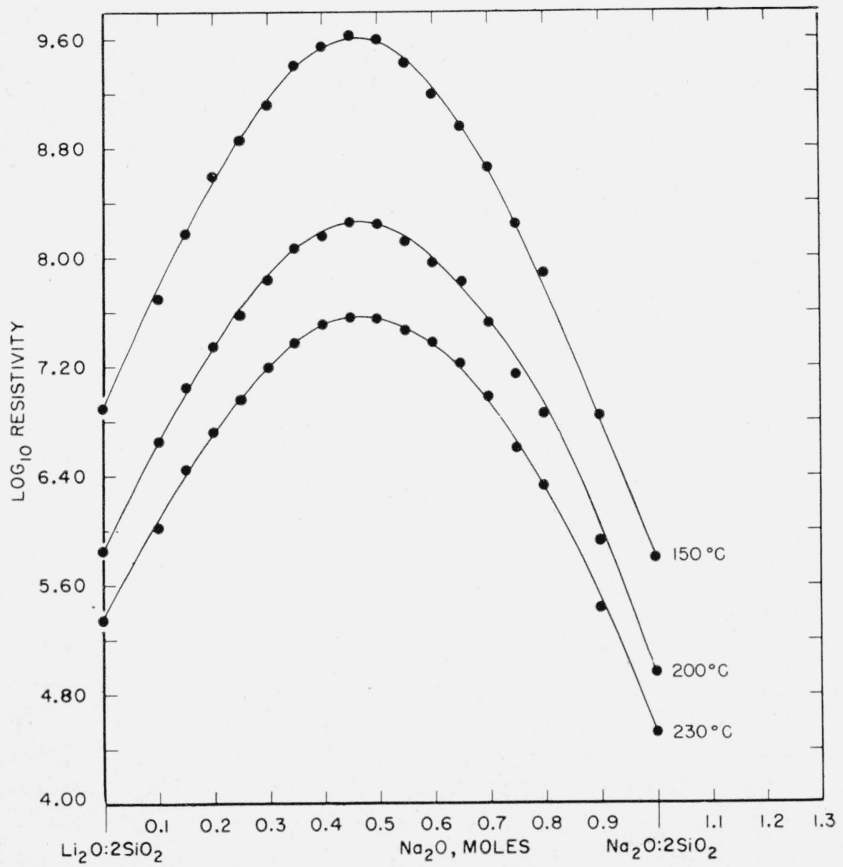

FIGURE 1. Resistivity-composition isotherms at $150^{\circ}, 200^{\circ}$, and $230^{\circ} C$ for glasses in the system $x \mathrm{Li}_{2} \mathrm{O}:(1-x) \mathrm{Na}_{2} \mathrm{O}: 2 \mathrm{SiO}_{2}$ where $x$ ranges from 0 to 1 . either one, the smaller quantities of each separate ion can find interstices which come close to fitting them and the number left in interstices too large for them is much smaller than when either single ion is used." In this connection Stevels [5], in discussing dielectric losses in glasses, stated: "If in a glass containing only one kind of network modifier, some of these ions are replaced by other network modifiers having a different radius, then a more compact network can be obtained." Hence, both Smyth and Stevels suggested that a more compact structure results when a mixture of two alkali ions is substituted for the same mole percent of either one. The more compact packing in a lithium-sodium silicate over that in a binary silicate may be expected to increase the activation energy and make it more difficult for the ions to migrate through the structure. This assumption is consistent with the data presented in figures 1 and 2 . Following the reasoning presented by Smyth and by Stevels, the maxima on both the resistivity-composition and heat-of-activation-composition curves suggest that a lithiumsodium silicate containing approximately equimolar quantities of lithium oxide and sodium oxide has a more compact structure than that of any other composition in the system $x \mathrm{Li}_{2} \mathrm{O}:(1-x) \mathrm{Na}_{2} \mathrm{O}: 2 \mathrm{SiO}_{2}$.

Because ternary lithium-sodium silicates had higher resistivities than the binary compositions, the question arises whether quaternary alkali silicates would have still higher resistivities. By analogy with Smyth's reasoning, it might be expected that when a mixture of three alkali ions is substituted for any of the three, the smaller quantities of each separate ion should find interstices that come close to fitting them, and the number left in interstices too large for them should be smaller than when

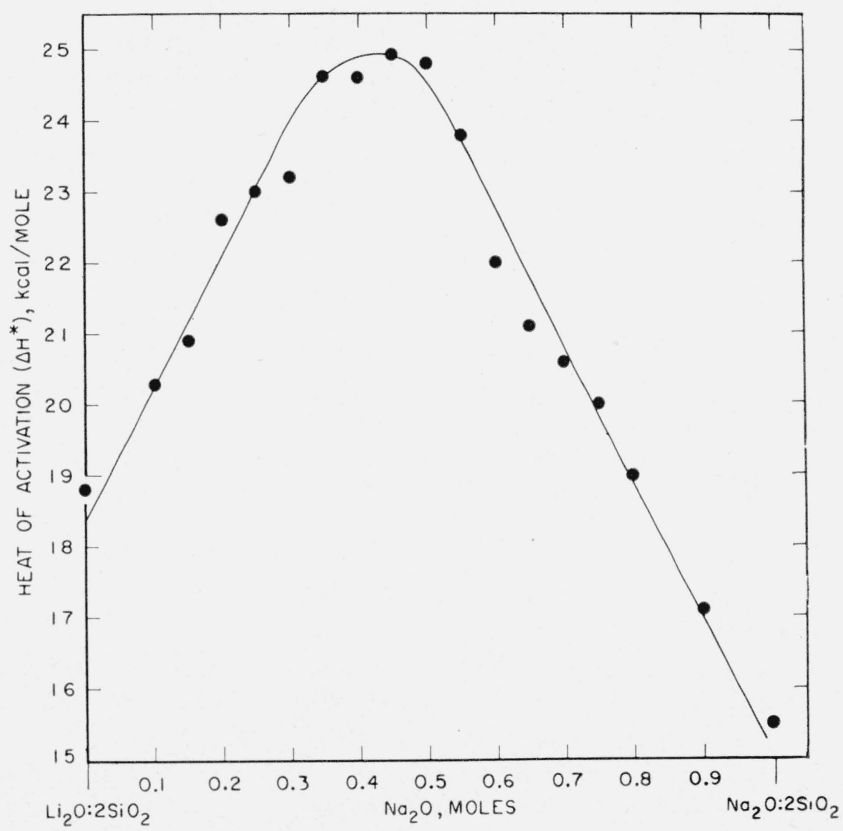

FIGURE 2. Heat of activation-composition curve for glasses in the system $x \mathrm{Li}_{2} \mathrm{O}:(1-x) \mathrm{Na}_{2} \mathrm{O}: 2 \mathrm{SiO}_{2}$ where $x$ ranges from 0 to 1 . 
either single ion is used or when two alkali ions are used. Results obtained on glasses in a system such as $x \mathrm{Li}_{2} \mathrm{O}: y \mathrm{Na}_{2} \mathrm{O}:(1-x-y) \mathrm{K}_{2} \mathrm{O}: 2 \mathrm{SiO}_{2}$ should clarify this point. Such a study should yield information that would be useful not only in the elucidation of the structure of glass but also in the design of glasses and ceramic coatings of specified resistivities. In this connection it would also be desirable to study systematically the resistivities of alkali-free glasses in which a nonalkali ion is replaced by the same mole percent of two or more isovalent ions.

\section{Summary}

Resistivity data were presented for sodium disilicate, lithium disilicate, and a series of 16 ternary lithium-sodium silicates prepared by the substitution of sodium oxide for lithium oxide in a base composition $\mathrm{Li}_{2} \mathrm{O}: 2 \mathrm{SiO}_{2}$.

The results were interpreted on the basis that the substitution of two alkali ions for the same mole percent of either one leads to a more compact structure which decreases ionic migration.

The variation in resistivity with change in composition was found to be similar to that reported by
Dale, Pegg, and Stanworth [2] in their study of five compositions in the five-component lithium-sodiumaluminum borosilicate system. In addition, it was found in the present investigation that the heats of activation varied with change in composition in the same manner as did the resistivity.

\section{References}

[1] S. W. Strauss, L. E. Richards, and D. G. Moore, Effect of temperature on the electrical resistivity of several ceramic and silicone-type coatings, ASTM Sp. Tech. Publ. No. 153, 101-8 (1953).

[2] A. E. Dale, E. F. Pegg, and J. E. Stanworth, The electrical properties of some lithia containing glasses, J. Soc. Glass Technol. 35, 136 (1951)..

[3] H. T. Smyth, Dielectric losses in glass, Tech. Rept. No. 9 (Rutgers University, 1955).

[4] M. Tashiro, Measurement and evaluation of electrical potentials between glasses, ONR Tech. Rept. No. 60 (1954).

[5] J. M. Stevels, Dielectric losses in glasses, Philips Tech. Rev. 13 [2], 365 (1952).

[6] S. W. Strauss, D. G. Moore, W. N. Harrison, and L. E. Richards, Fundamental factors controlling electrical resistivity in vitreous ternary lead silicates, J. Research NBS 56, 135 (1956) RP2658.

Washington, December 23, 1955. 